تعيين سهم زيرحوضهها در توليد رسوب با استفاده از ويزگىهاى يذيرفتارى مغناطيسى رسوبات و مدل تر كيبى عدم قطعيت (مطالعه موردى: حوضه آبخيز آشان، شهرستان مراغه)

\author{
كاظم نصرتى "، مصطفى امينى'، آرمان حدادجى 'و محمدرضا زارع
}

كلمات كليدى: منشايابى رسوب، حوضه آبخيز آشان، فرسايش، مدل تركيبى بيسين، ويزگى هاى يذيرفتارى مغناطيسى

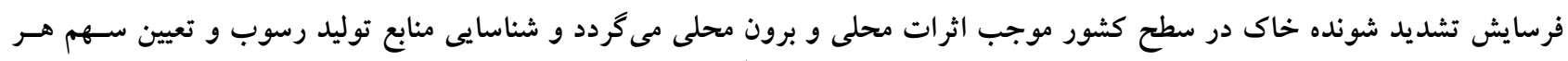

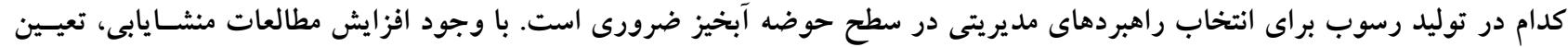

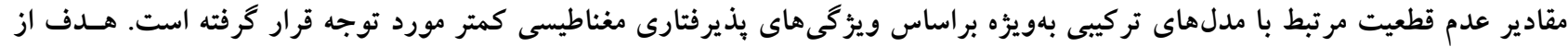

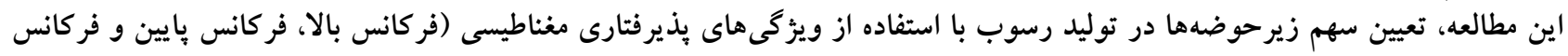

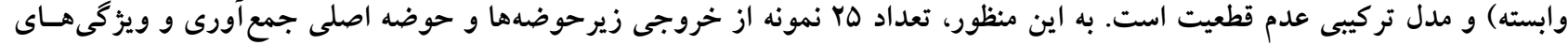

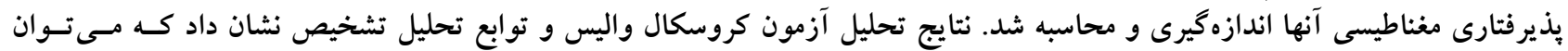

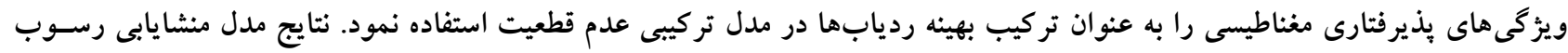

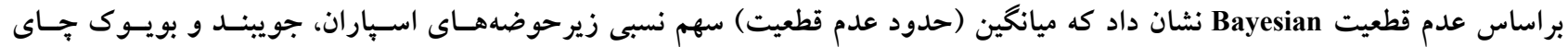

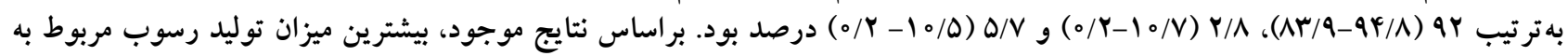

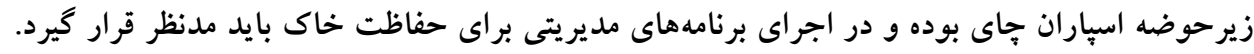

ا. كروه جغرافياى طبيعى، دانشكده علوم زمين، دانشخاه شهيد بهشتى، تهران، ايران

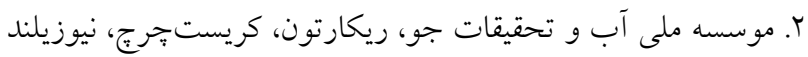
r. كروه فيزيك دانشخاه مالك اشتر شاهين شهر اصفهان

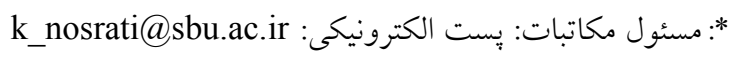


دهه اخير، استفاده از ويزگگىهاى فيزيكسى و شـيميايى رسـوبات

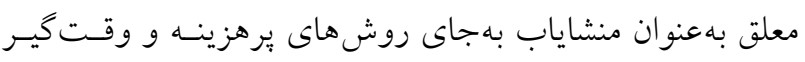

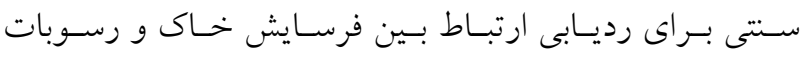

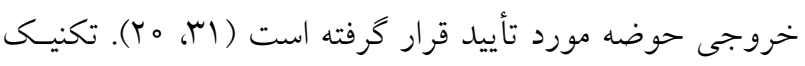

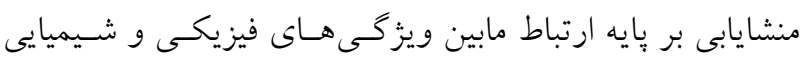

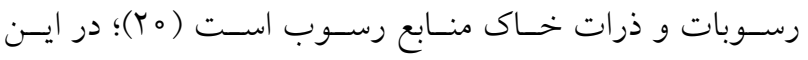

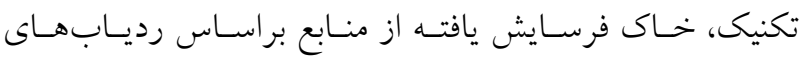

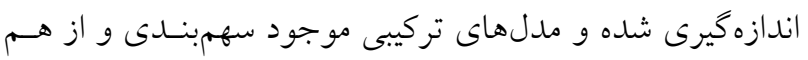

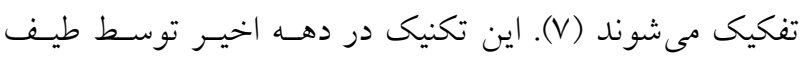

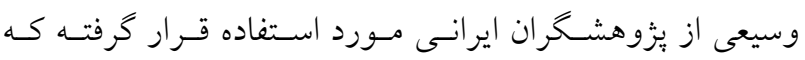

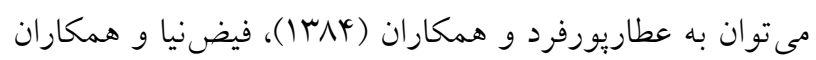

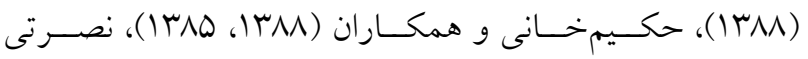

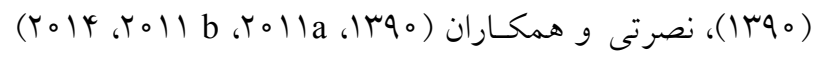

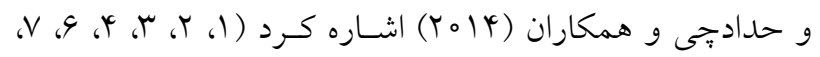

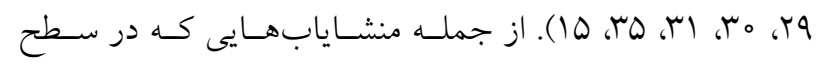

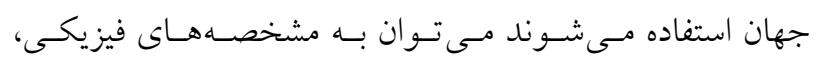

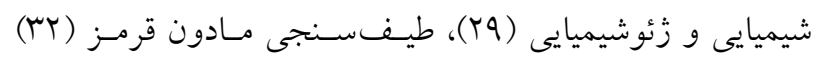

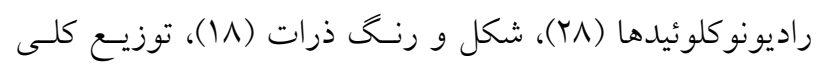

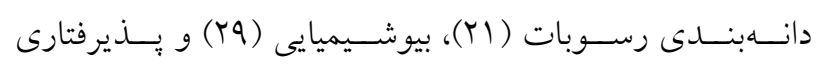

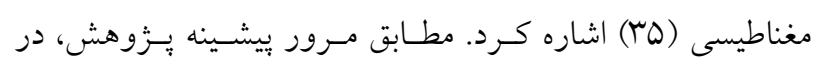

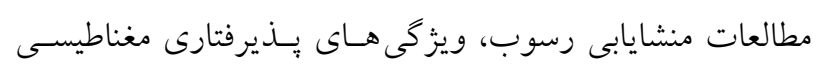
بهنوان ردياب، كمتر مورد توجه قرار كرفته است.

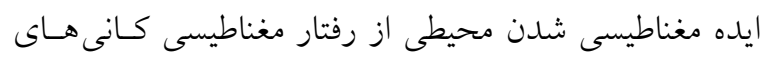

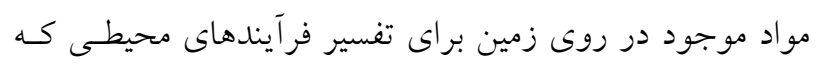

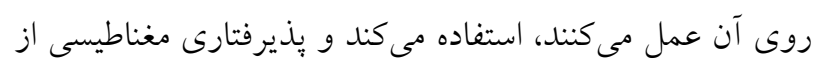

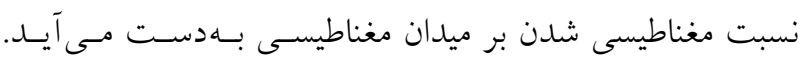

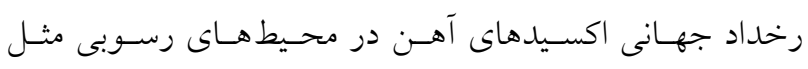

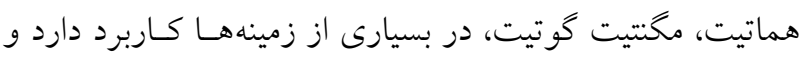

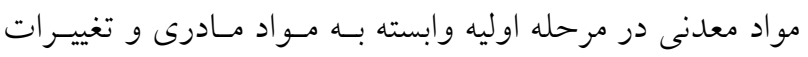

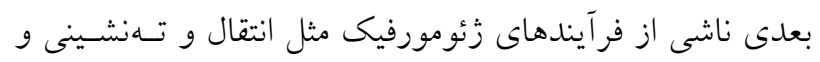

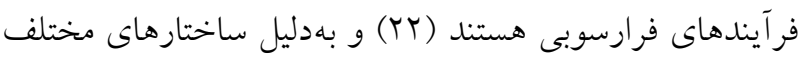

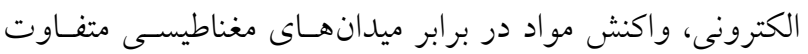

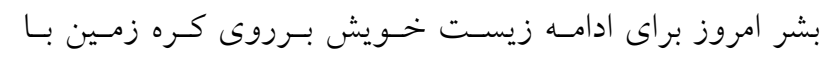

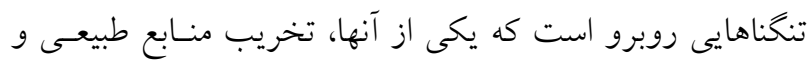

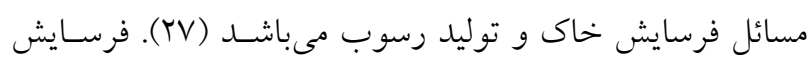

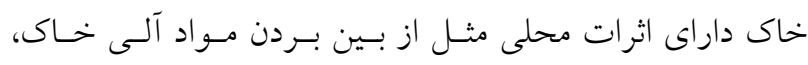
كاهش توليدات كشاورزى و تهديد امنيت غذايى بشـر و اثـرات

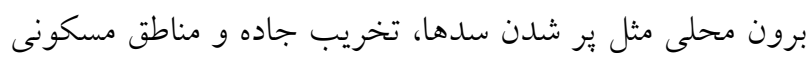

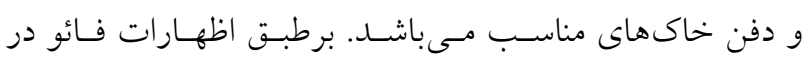

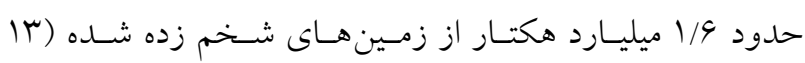

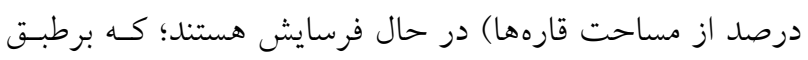

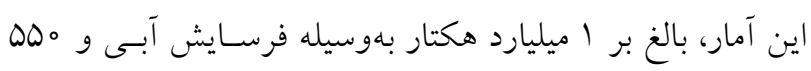

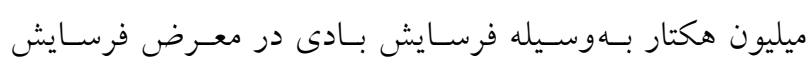

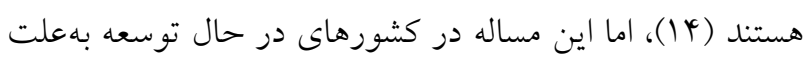

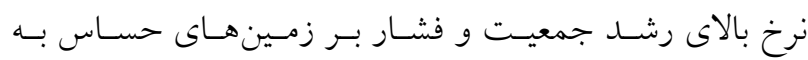

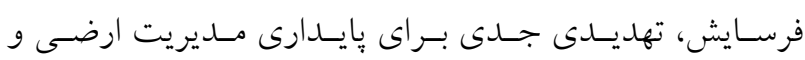

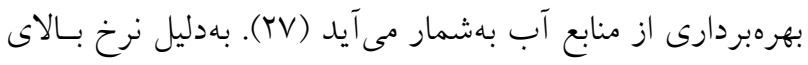

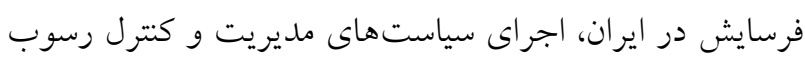

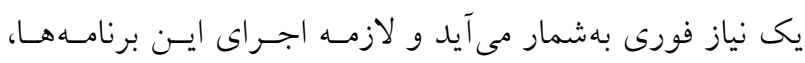

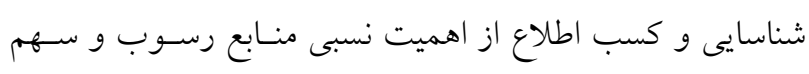

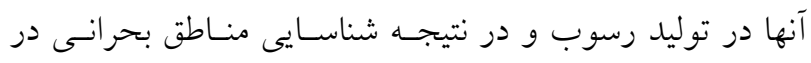

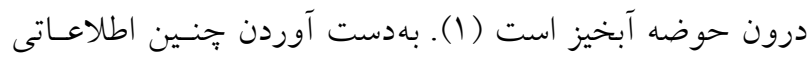

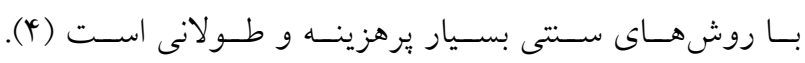

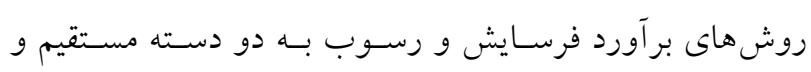

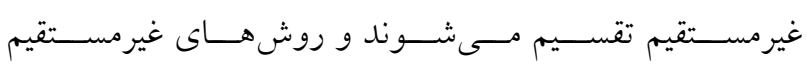

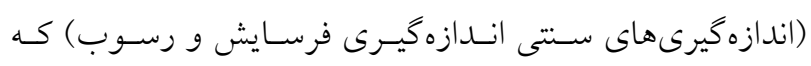

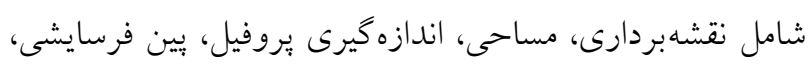

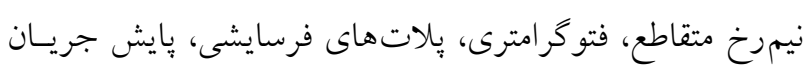

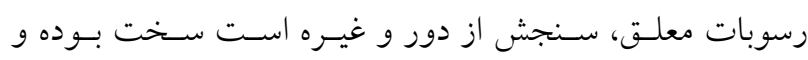

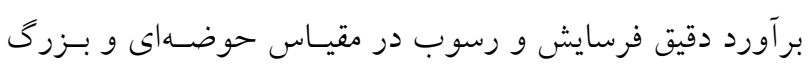

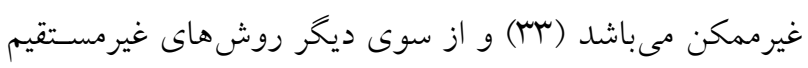
بهدليل تغييريذيرى فرسايش در مقيـاس زمـانى و مكـانى در آن

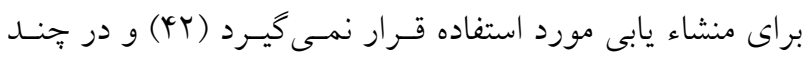


مغناطيسى وابسـته بـهـ بسـامد اقـدام بـه منشـايابى رسـوبات در حوضههاى آبخيز مختلف استان سمنان كـردهانــ از كروسـكال

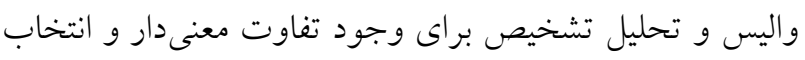

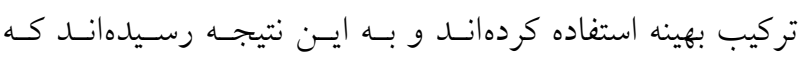
فركانس وابسته قابليت خوبى در تفكيك منابع رسوب دارد (^).

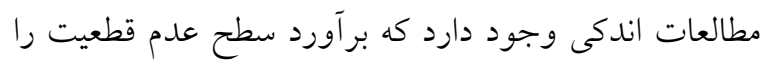
در رويكرد منشايابى رسوب در تعيين سهم نسبى هـر يـك از

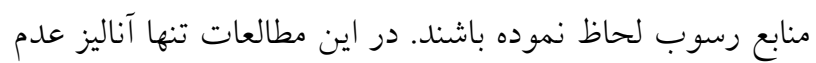

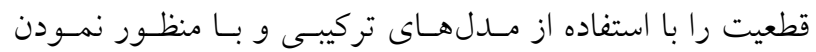
تغييرات مكانى ويزگى هاى ردياب براى تعيـين حسدود اطمينـان تخمين هاى مدل براسـاس رويكـرد شـبيهسـازى مونست كـارلو

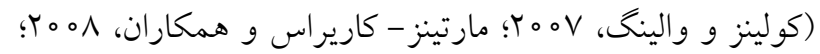

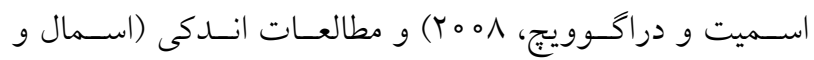

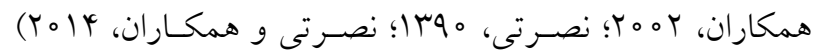

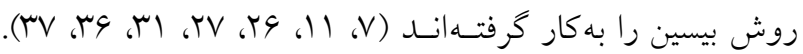

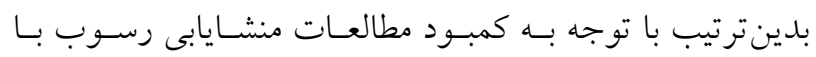

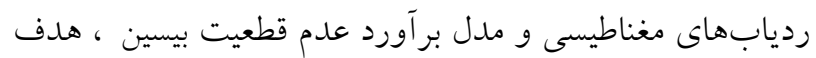

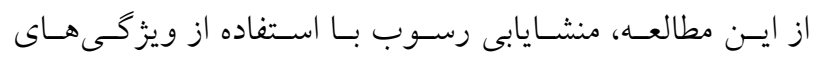

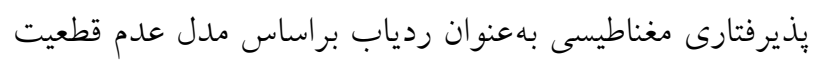

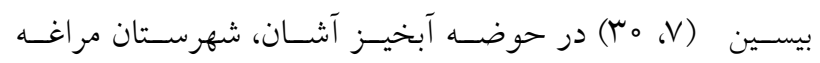

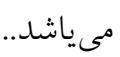

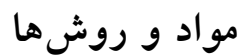

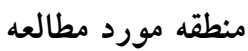

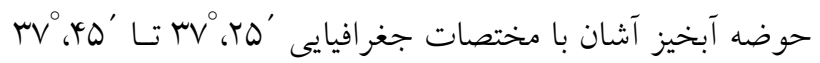

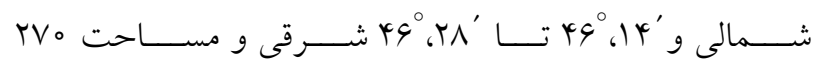

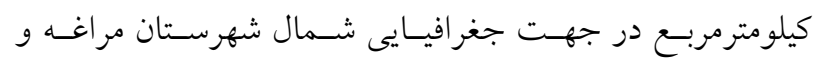
جنوب غربى استان آذربايجان شرقى واقع شده است (شكل (1). اين حوضه داراى سه زيرحوضه اصلى به نامهاى اسباران جـاى،

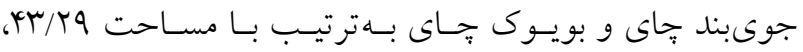

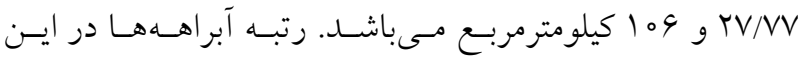

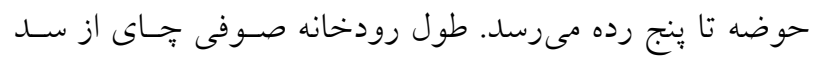

بوده و اين تشخيص مابين منابع و فر آيندهاى مختلف را فـراهم

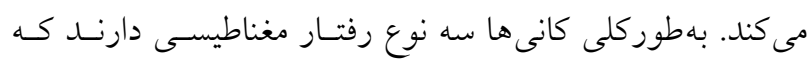

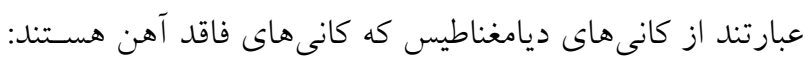

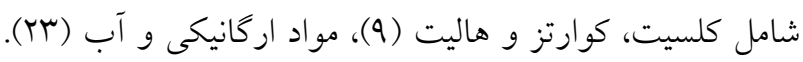

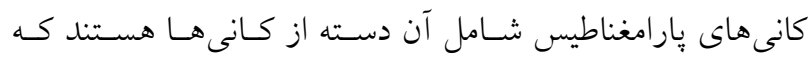

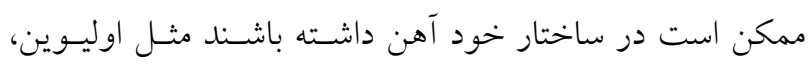

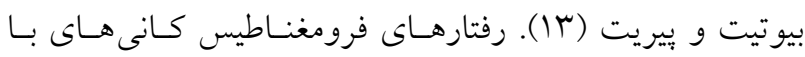

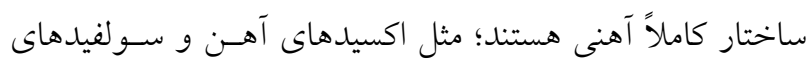

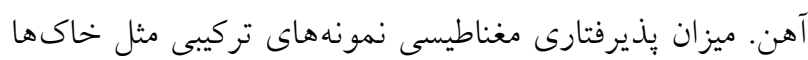

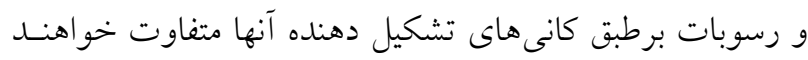
بود (19). اصول مغناطيسى شدن محيط رسوبى در مرحله اوليـه

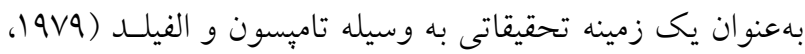
1919) كه براساس تكنيكهاى مغناطيس سنگ بايه كذارى شـده

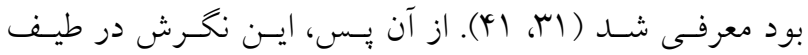

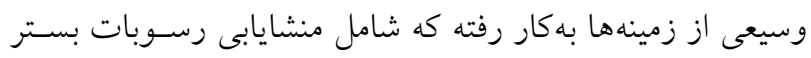

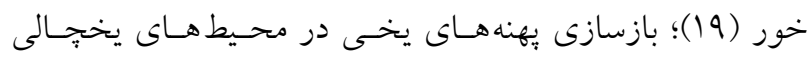

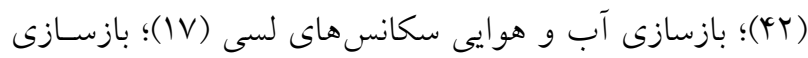

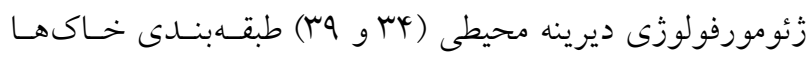

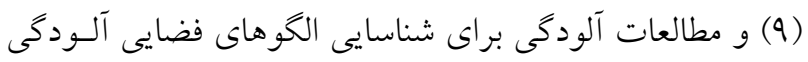

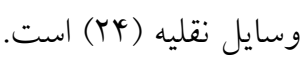

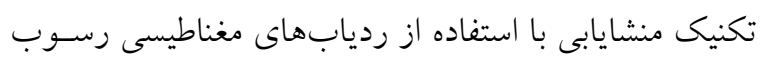

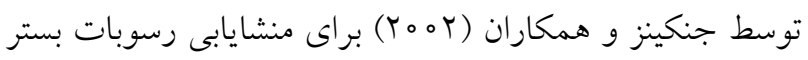

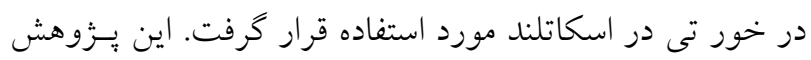

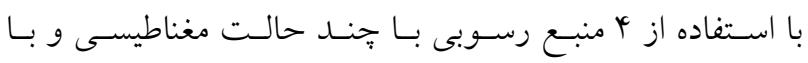

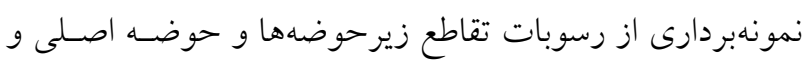

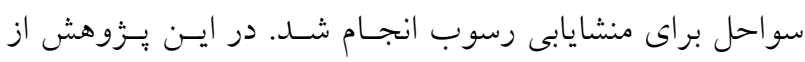

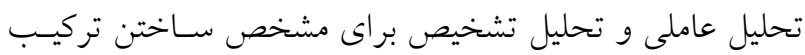

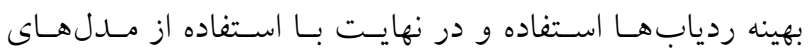
غيرتركيبى اقدام بـه شناسـايى سـهم نسـبى رسـوبات در منـابع

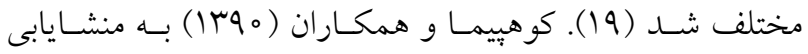

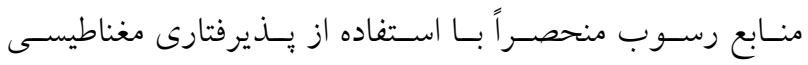

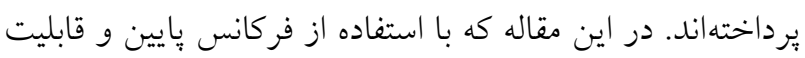




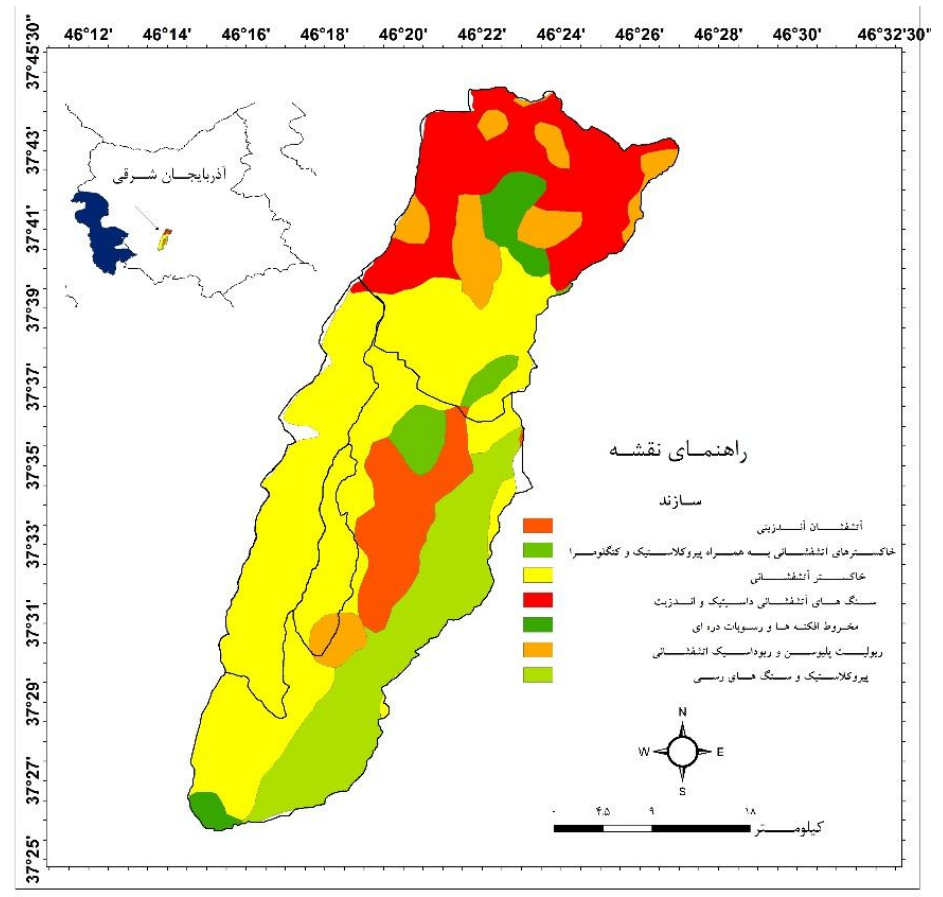

شكل ا موقعيت جغرافيايى و سازندهاى زمينشناسى موجود در حوضه آبخيز آشان

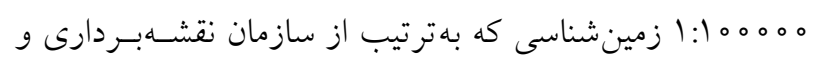
زمينشناسى كشور تهيه شده بودنـا در محـيط GIS بــردازش و

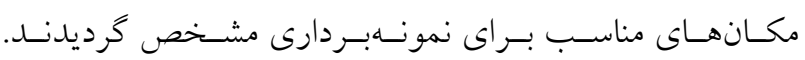
رسوبات تازه تهنشين شده در خروجى كف آبراهههاى هر كدام از زيرحوضهها به طول سه كيلومتر از خروجى حوضه برداشـت

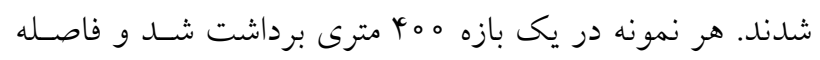

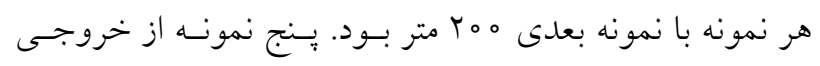

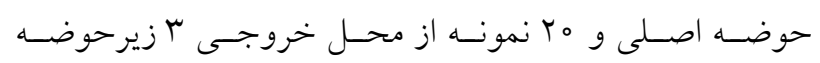

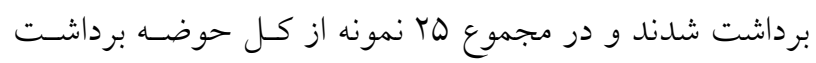

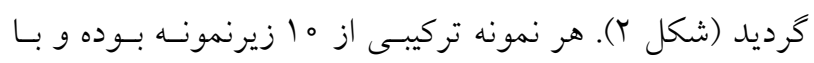
فاصله م+ متر از هم برداشت شدند.

اندازهگيرى ويزگ هاى بذير فتارى مغناطيسى رسوبات

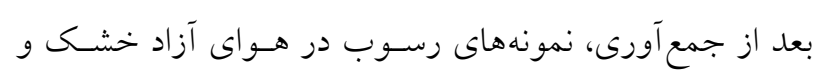

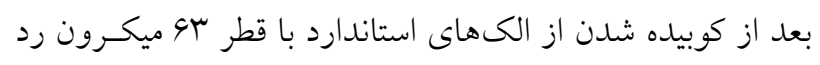

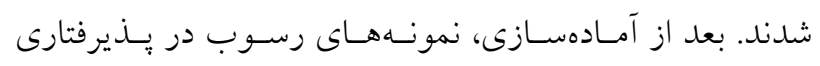

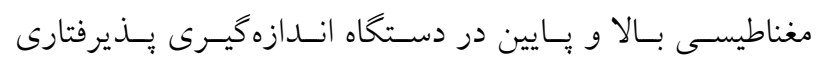
مغناطيسى در واحد CGS (كرم بر سانتى متر مكعب) در موسسه
علويان تا رأس حوضه بويوك جاى به

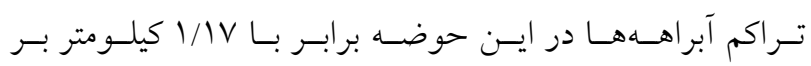

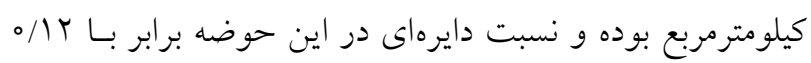
مىباشد و مفهوم آن اين است كه شكل حوضه دايرهاى نيستـ. حداقل و حداكثر شيب در ايسن حوضـه بـهـترتيـب صـفر و و درصد است. سازندهايى كه بيشترين مساحت در حوضه آبخيـز

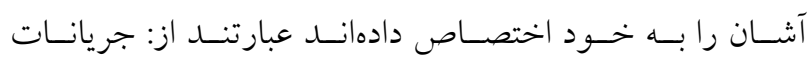
خاكسـترهاى آتشفشـانى، سـنخهــاى آتشفشـانى دياسـتكى و آندزيت، سنخهاى رسى و بيرو كلاستيك. كـاربرى اراضسى در اين حوضه از تنوع كمترى برخوردار بوده و شامل مرتـع (غنس، متوسط و فقير)، زمسينهـاى كشـاورزى (ديسم و آبـى) و مراكـز انسانى مى باشد و بيشترين مساحت كاربرى مربوط بـه كـاربرى

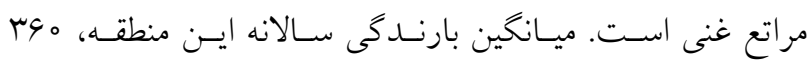
ميلى متر در سال و متوسط دماى سالانه آن از N/V تا ه/ ا درجه سانتى گر اد در نوسان مىباشد. نمونهبردارى

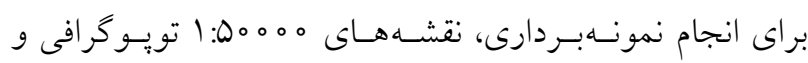




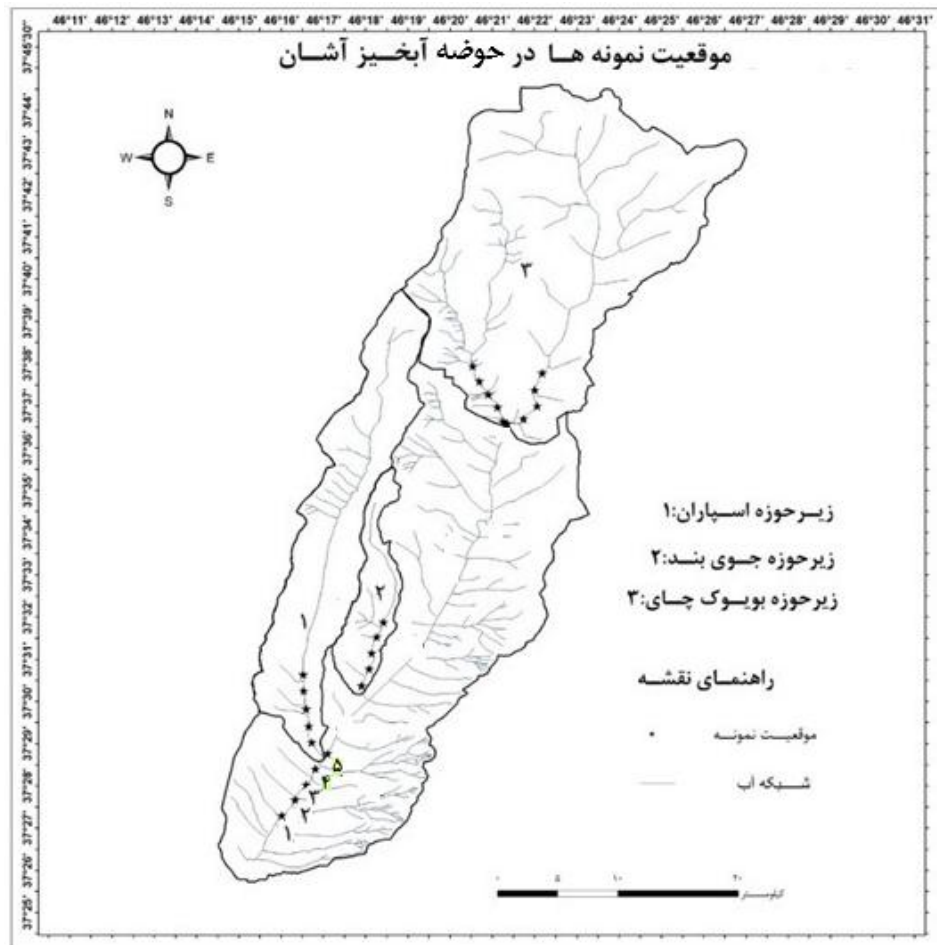

شكل r موقعيت نمونه ماى رسوب حوضه آبخيز آشان

درصسورتى كـهـ مـواد موجـود در رسـوبات در برابـر ميـدان مغناطيسى قرار كيرند مطابق رفتار اين رسوبات در برابـر ميـدان

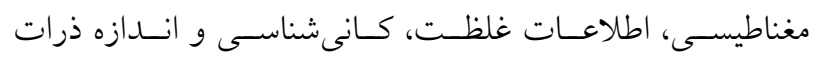

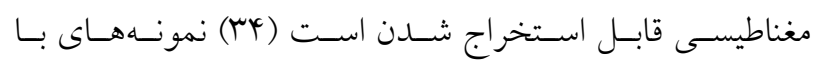

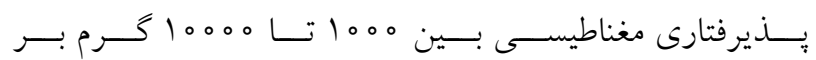

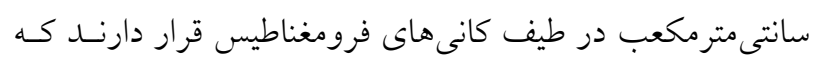

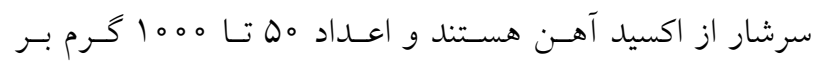

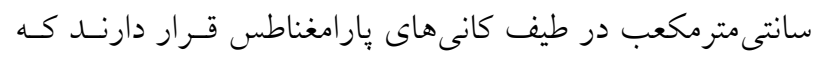

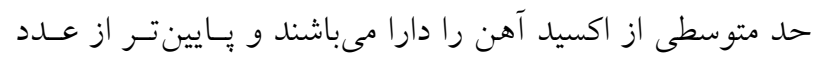

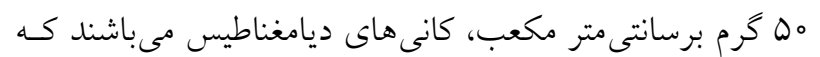

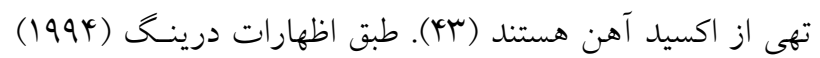

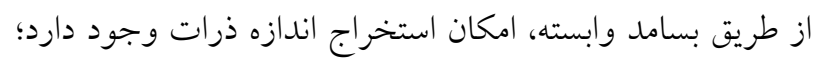

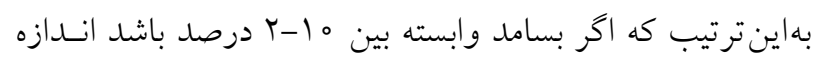
ذرات در حد ميانكين (ذرات درشت بههمراه ذرات كوجنكتر از

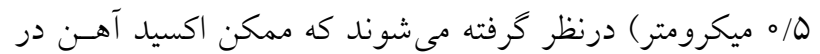

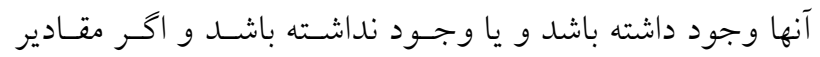

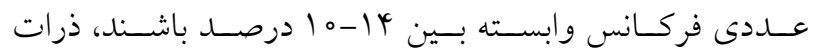

زُئوفيزيك دانشكاه تهران اندازهيرى شدند. با توجه به ضرورت

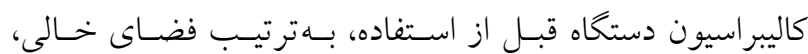
كربنات منكنز يـا آب و فضـاى خـالى توسط سنسـور دستيّاه

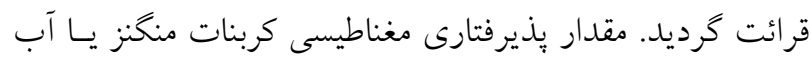

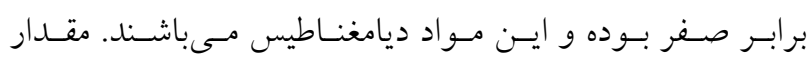

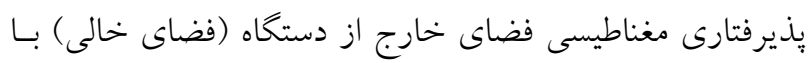
توجه به اثرات خارجى بايد مشخص كرديده تا در نتايج نهايى دئي

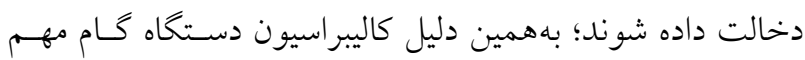

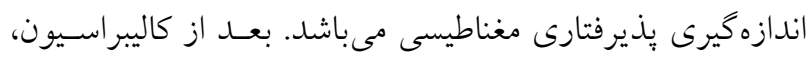

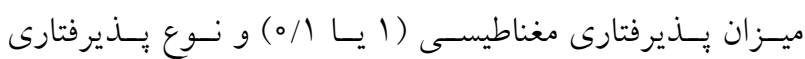

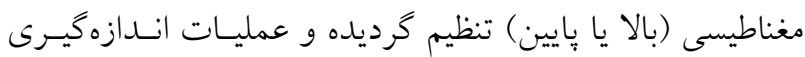

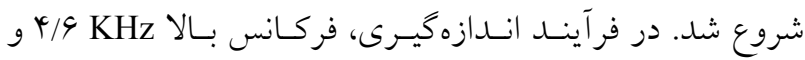

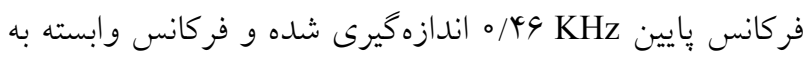
فركانس با توجه به اينكه بهعنوان يك ردياب درنظر كرفته شــد از طريق رابطه (1) محاسبه كرديد.

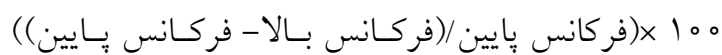

$$
\text { = فر كانس وابسته. }
$$


年 $f_{q}$

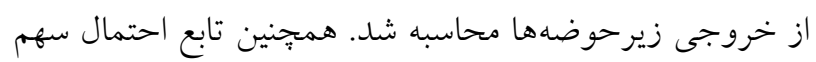

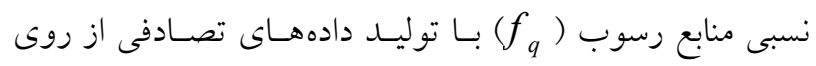

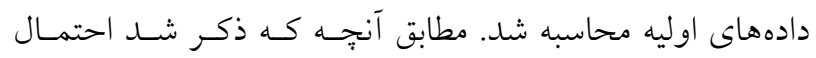

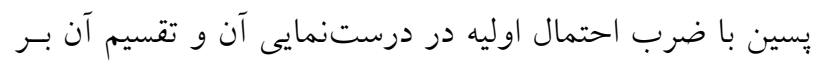

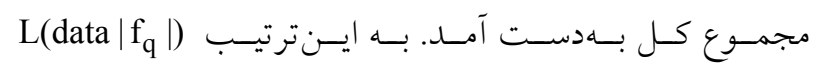

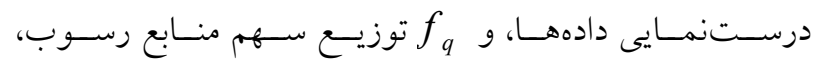

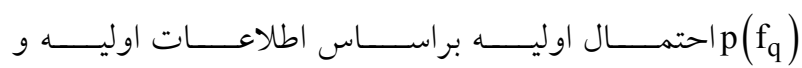
L(data $\left.\left|f_{q}\right|\right) \times p\left(f_{q}\right)$

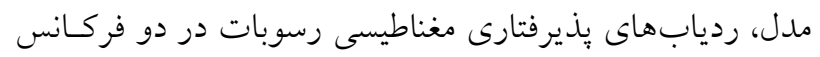

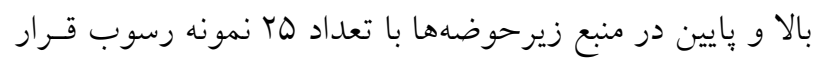

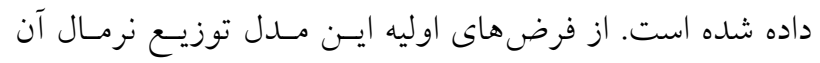
است؛ به عبارت ديخر فرض مىشود توزيع دادهها نرمال اسـت.

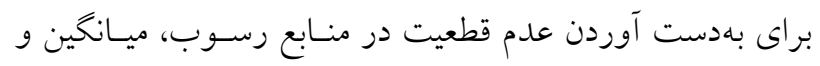

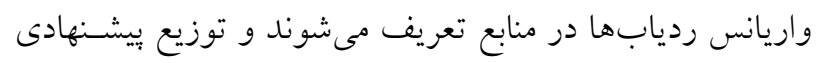

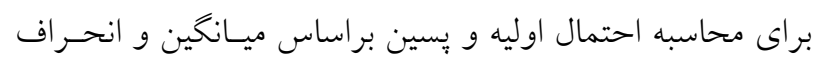

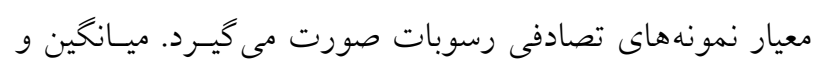

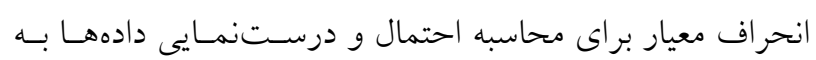
شكل زير محاسبه مىشود (روابط با، با و ه): $\mu=\sum_{\mathrm{i}=1}^{\mathrm{n}}\left(\mathrm{f}_{\mathrm{i}} \times \mathrm{m}_{\mathrm{j}_{\text {sourcei }}}\right)$ $\left.\mu=\sqrt{\sum_{i=1}^{n}\left(f_{i}^{r}\right.} \times s_{\text {sourcei }_{i}^{r}}\right)$

$\mathrm{L}\left(\mathrm{x} \mid \mu_{\mathrm{j}}, \sigma_{\mathrm{i}}\right)=\prod_{\mathrm{k}=1}^{\mathrm{n}} \prod_{\mathrm{j}=1}^{\mathrm{n}}\left[\frac{1}{\sqrt{r \pi \sigma^{r}}} \times \mathrm{e}^{\frac{(\mathrm{x}-\mu)^{r}}{r \sigma^{r}}}\right]$

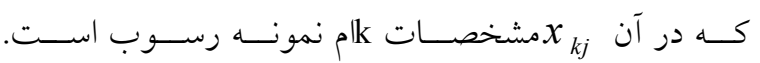
درست نمايى سهم نسبى منابع رسـوب f $f_{q}$

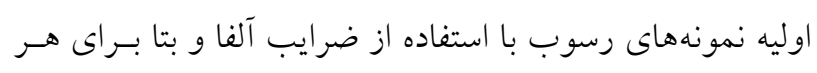

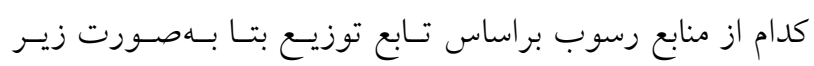
محاسبه مىشود (رابطه 9):

$p\left(f_{q} \mid \alpha_{i}, \beta_{i}\right)=\prod_{k=1}^{n} \frac{f_{i}^{\alpha_{i-1 \times\left(1-f_{i}\right)} \beta_{i-1}}}{B\left(\alpha_{i}, \beta_{i}\right)}$

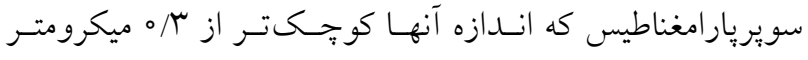

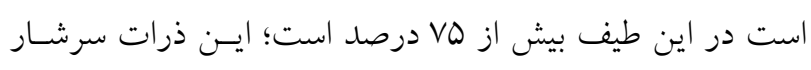

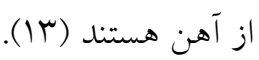

\section{تفكيك منابع رسوب}

براى انجام منشايايى، در كام اول بهدست آوردن تركيب بهينهاى از رديابها كه قابليت تشخيص و تفكيك منابع را داشته باشــند

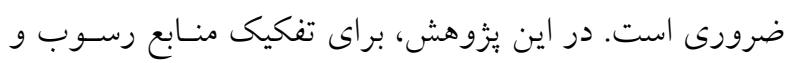

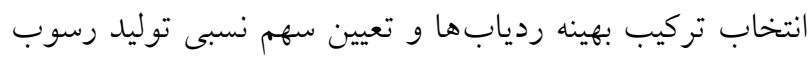

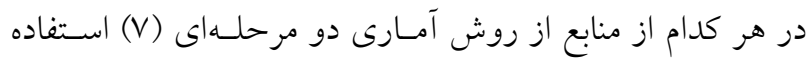

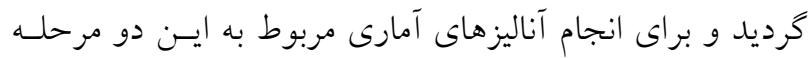

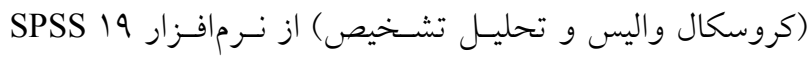

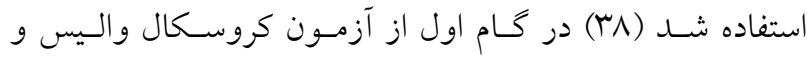
سبس بهمنظور انتخاب تركيب بهينه رديـابهــا كـهـ در آزمـون كروسكال واليس مورد يذيرش واقع شده بودند از تـابع تحليـل ترديل

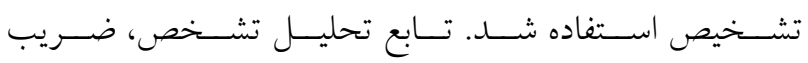

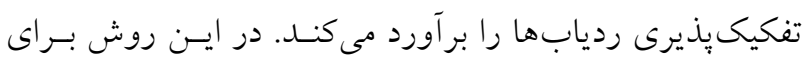

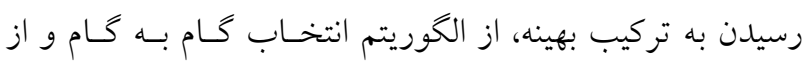

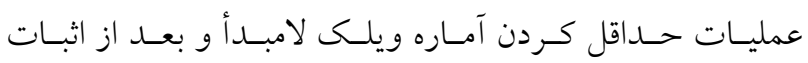

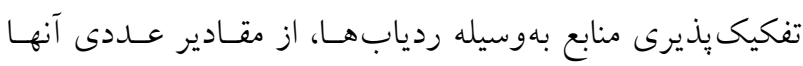

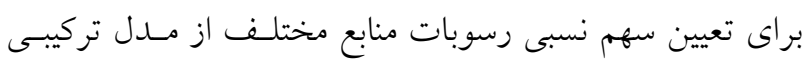

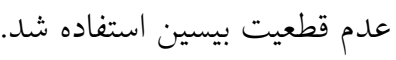
تعيين سهم نسبى منابع رسوب

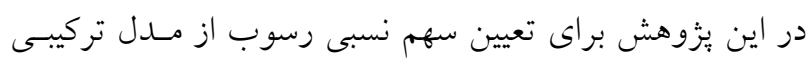

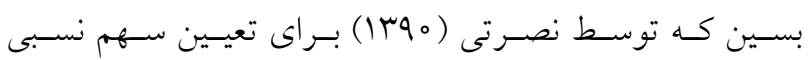

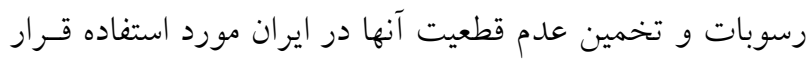

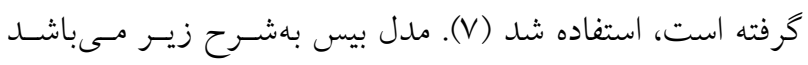

(رابطه Y):

$$
\begin{aligned}
& \mathrm{p}\left(\mathrm{f}_{\mathrm{q}} \mid \text { data }\right)=\frac{\mathrm{L}\left(\text { data } \mid \mathrm{f}_{\mathrm{q}}\right) \times \mathrm{p}\left(\mathrm{f}_{\mathrm{q}}\right)}{\sum \mathrm{L}\left(\text { data } \mid \mathrm{f}_{\mathrm{q}}\right) \times \mathrm{p}\left(\mathrm{f}_{\mathrm{q}}\right)} \\
& \text { در اين مدل، توابع احتمال سهم نسبى براى هر منبع رسـوب } 1 \mathrm{r})
\end{aligned}
$$


منبع زير حوضه داراى تفاوت معنسى دار هسـتند. بـهايسن ترتيـب،

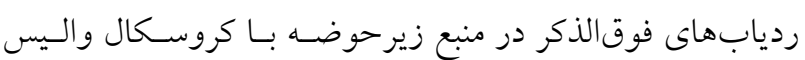

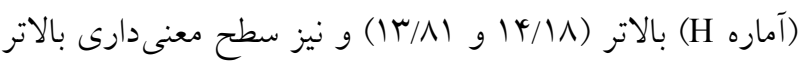

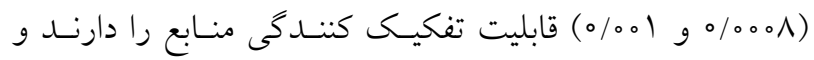

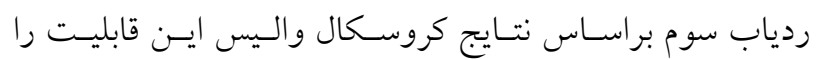
ندارد. بعد از آزمـون H نيـاز هسـت تـا تركيـب بهينـه رديـابهــا مشخص شود. براين اساس، دو ردياب فركانس بالا و پـايين در

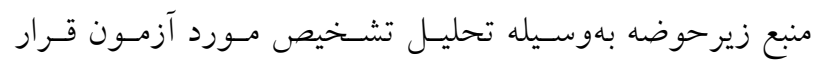

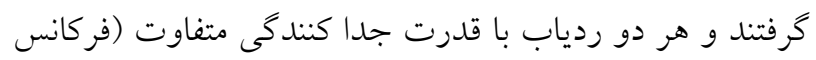

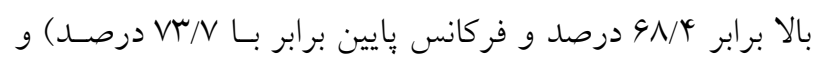

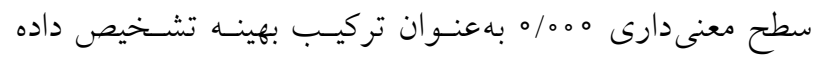
شدند (جدول r) و قدرت جدا كندكى هر دو ريـاب بـاهم در

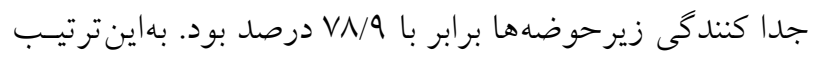

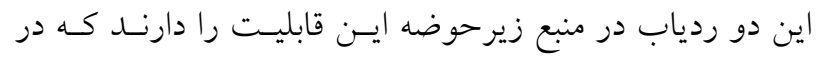
مدل تعيين سهم نسبى رسوب شركت داده شوند. بلهمنظور نمايش الكوى تغييرات مكانى دو رديـاب در منسابع

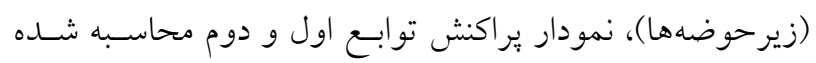

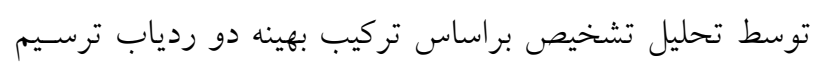

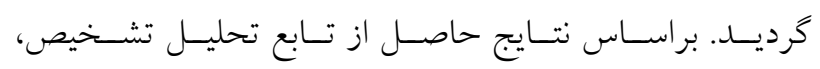

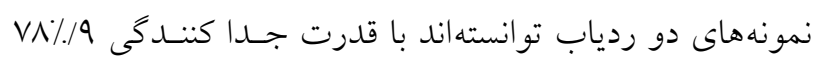

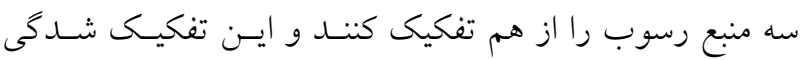

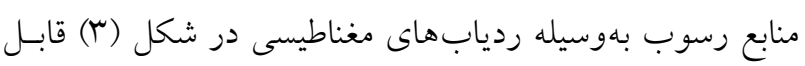

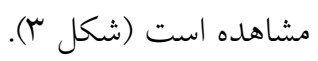

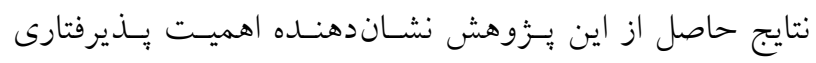

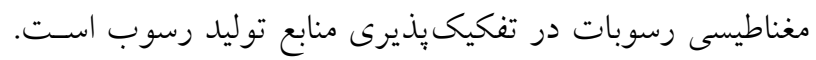

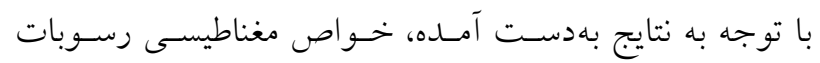

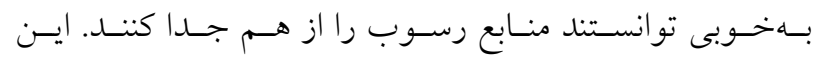

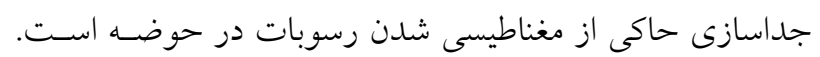

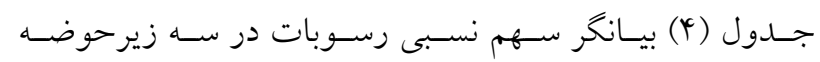

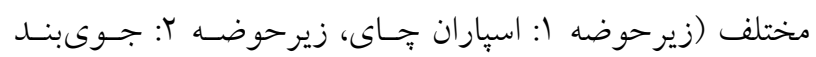

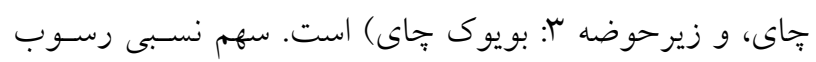

درنهايت درسـتنمـايى اطلاعـات اوليسه در درسـتنمـايى نمونهاى رسوب بهمنظـور محاسـبه احتمـال بِسين غيرنرمـال

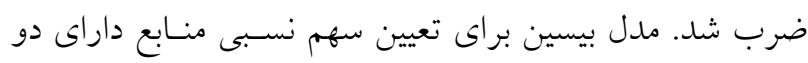

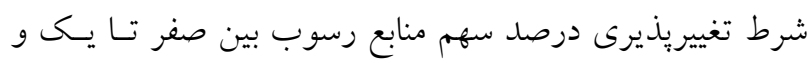

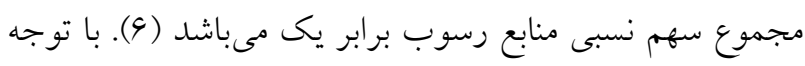

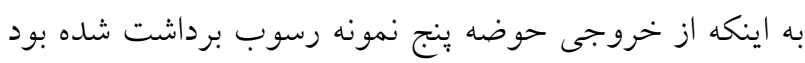

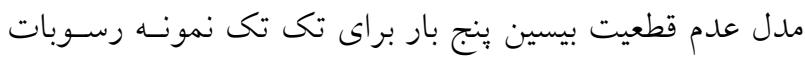

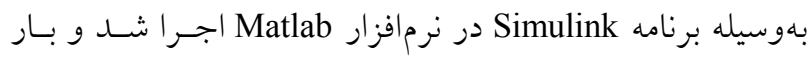

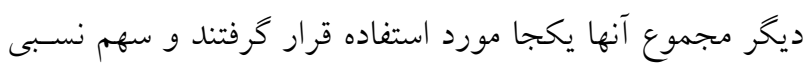

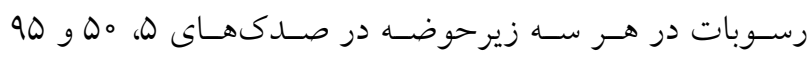

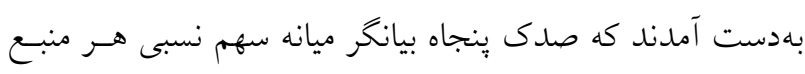

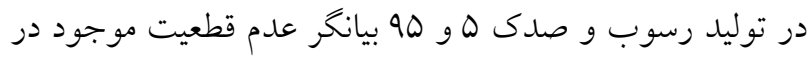
منابع توليد رسوب هستند.

\section{نتايج و بحث}

نتايج حاصـل از آناليزهـاى آزمايشـاهى در جــدول ( (1) آمــهـ

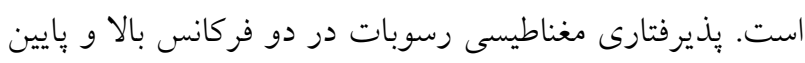

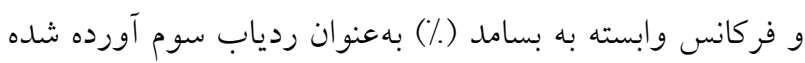

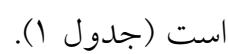

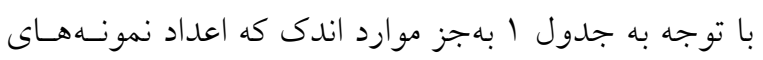

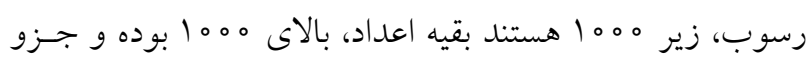

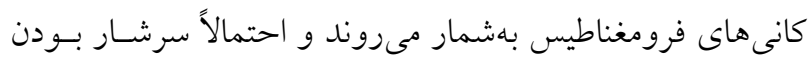

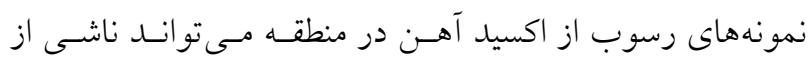

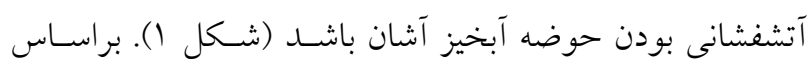

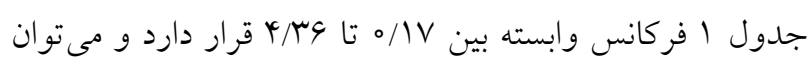

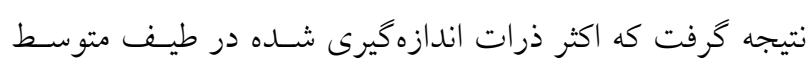

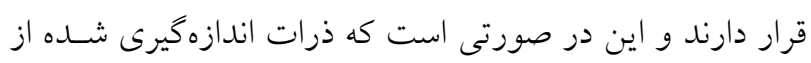
الكى سوميكرون عبور داده شدهاند.

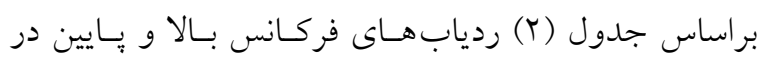

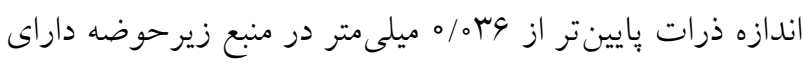

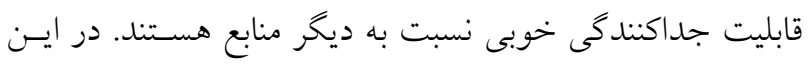

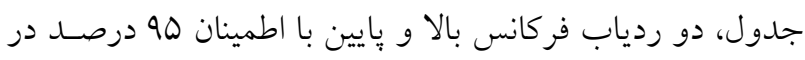


جدول ا ميانكين بذيرفتارى مغناطيسى رسوبات كوجکكتر از بهو ميكرون در حوضه آبخيز آشان

كد ا: زيرحوضه اسياران، كد ب: زيرحوضه جوىبند، كد با: زيرحوضه بويوك جايى

$$
\text { يذيرفتارى مغناطيسى منابع رسوب }
$$

\begin{tabular}{|c|c|c|c|c|c|c|c|}
\hline $\begin{array}{c}\text { فر كانس بالا } \\
\left(x \times 10^{-9} \mathrm{~g} / \mathrm{cm}^{-r}\right)\end{array}$ & $\begin{array}{c}\text { فر كانس بايين } \\
\left(x \times 10^{-9} \mathrm{~g} / \mathrm{cm}^{-r}\right)\end{array}$ & وفر كانس & $\begin{array}{l}\xi \\
\xi \\
\xi\end{array}$ & $\begin{array}{c}\text { فركانس بالان } \\
\left(x \times 10^{-9} \mathrm{~g} / \mathrm{cm}^{-r}\right)\end{array}$ & $\begin{array}{c}\text { فركانس بايين } \\
\left(x \times 10^{-9} \mathrm{~g} / \mathrm{cm}^{-r}\right)\end{array}$ & فرابست \% فانس & $\xi$. \\
\hline$|N| N / G K$ & $|\wedge \Delta| / \Lambda$ & $1 / v 9$ & 1 & $119 \mathrm{~V} / 9 \mathrm{~T}$ & $11 V \pi / \wedge 9$ & .01 & $r$ \\
\hline$M|\Psi| / T \Delta$ & $r k \psi Q / \circ{ }^{*}$ & - TSQ & 1 & $119 \mathrm{~V} / 9 \mathrm{~T}$ & $11 \Lambda \circ / 4 V$ & $1 / 09$ & $r$ \\
\hline TMYT/I & $T M G \circ / 4$ & $1 / 94$ & 1 & $1 K T q / 9$ & $1 \times 90 / 49$ & $r / N I$ & r \\
\hline TOYQ/AT & $r \mid r K / r V$ & $1 / 90$ & 1 & $1+49 / 9 V$ & $\mid K \Psi Y / T F$ & $4 / M^{\prime}$ & r \\
\hline$r \mid r k / 4 y$ & r/QV/VA & T/4 & 1 & $9 \wedge 4 / 09$ & $৭ \Lambda \Lambda / \Gamma \wedge$ & & $r$ \\
\hline$r \Pi$ r/AD & $T M N / 9 V$ & $1 / 91$ & ميانكين & $11 r \mid / 19$ & $11 r \% / v$ & -/va & $r$ \\
\hline $0.1 / V^{k}$ & YMN/NT & ס/AY & انحر اف & $1 \circ \mu / \wedge$ & 1. HN/GY & - NQ & $r$ \\
\hline $1990 / 94$ & $1919 / 100$ & $1 / Q 4$ & $r$ & $11 N 1 / \Delta T$ & $|r Y q / q|$ & $r / q r$ & r \\
\hline $1009 / .9$ & $|\Delta \Lambda V / \mu|$ & VAI & $r$ & IIVG/IF & سז/תו11 & $0 / 91$ & $r$ \\
\hline $\mid K r / / 4$ & $\mid K Y V / F Y$ & $\circ / V Y$ & r & 1490 & $\mid$ Kro/NI & $Y / T G$ & $r$ \\
\hline $\mid T V / / 19$ & ITMN/KY & $1 / \mu r$ & r & ||$v q / 4 \mid$ & $\mid r \circ Y / A \circ$ & $1 / 90$ & $\ddot{\prime}$ \\
\hline roor/r & roY Yo/Tr & - /NF & r & ITH/KY & $\mid k \psi / 0 \Lambda$ & $1 / 99$ & $\begin{array}{l}8 \\
\frac{6}{6} \\
\frac{8}{4}\end{array}$ \\
\hline$|4| Q / \Delta 9$ & 1099100 & $1 / T 4$ & ميانخين & & & & \\
\hline 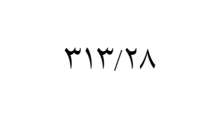 & $-19 / 19$ & $0 / 40$ & انحر اف & & & & \\
\hline \multicolumn{8}{|c|}{ يذيرفتارى مغناطيسى نمونههاى رسوب درخروجى حوضه آشان } \\
\hline $\begin{array}{c}\text { فر كانس بالا } \\
\left(x \times 10^{-4} \mathrm{~g} / \mathrm{cm}^{-r}\right)\end{array}$ & $\begin{array}{c}\text { فركانس بايين } \\
\left(x \times 10^{-9} \mathrm{~g} / \mathrm{cm}^{-r}\right)\end{array}$ & فر كانس & $\begin{array}{l}\xi . \\
\xi . \\
\vdots \\
\vdots\end{array}$ & $\begin{array}{c}\text { فركانس بالان } \\
\left(x \times 10^{-4} \mathrm{~g} / \mathrm{cm}^{-r}\right)\end{array}$ & $\begin{array}{c}\text { فركانس «ايين } \\
\left(x \times 10^{-4} \mathrm{~g} / \mathrm{cm}^{-r}\right)\end{array}$ & فرانس و فابس & $\begin{array}{l}\xi . \\
\xi \\
\xi \\
\dot{\xi}\end{array}$ \\
\hline $1 V 09$ & $r \mid \wedge Q / \Delta \wedge$ & $1 / 94$ & 1 & $I V \circ V / T Y$ & $10 \% 9 / V T$ & $r / 4 \lambda$ & r \\
\hline$r ৭ 90 / r^{4}$ & MIQN/TO & $\circ / \Lambda_{0}$ & r & rI99/4r & $1110 / 4$ & $0 / 19$ & o \\
\hline $\mid r<q / 4 \wedge$ & TYGYY & l/Ar & $r$ & & & & \\
\hline
\end{tabular}


جدول Y نتايج كروسكال واليس در بررسى توان رديابهاى مغناطيسى در جداسازى منابع رسوب

\begin{tabular}{|c|c|c|c|}
\hline سطح معنى دارى & آماره H & يذيرفتارى مغناطيسى & نوع منبع \\
\hline$\circ / \circ \circ \circ \wedge$ & $|Y /| \wedge k$ & فر كانس بالا & \multirow{3}{*}{ زيرحوضه } \\
\hline $0 / 001$ & $|r / \Lambda|$ & فركانس بايين & \\
\hline o/Ar & $0 \mu^{\prime}$ & فر كانس وابسته & \\
\hline
\end{tabular}

جدول ب نتايج تحليل تشخيص در حوضه آبخيز آشان

\begin{tabular}{|c|c|c|c|c|c|c|}
\hline $\begin{array}{c}\text { طبقهبندى صحيح } \\
\text { \% منابع }\end{array}$ & سطح معنى دارى & $\mathrm{F}$ & ويلكس لامبدا & يذ يرفتارى مغناطيسى & منبع & روش تحليل تشخيص \\
\hline $9 N / 4$ & $<0 / 001$ & $r q / 4 q$ & $0 / r \mid r$ & بالا & \multirow[b]{2}{*}{ زير حوضه } & \multirow[b]{2}{*}{ كام به گام } \\
\hline$V / \mathrm{V}$ & $<_{0 / 001}$ & rV/Ar & س & بايين & & \\
\hline
\end{tabular}

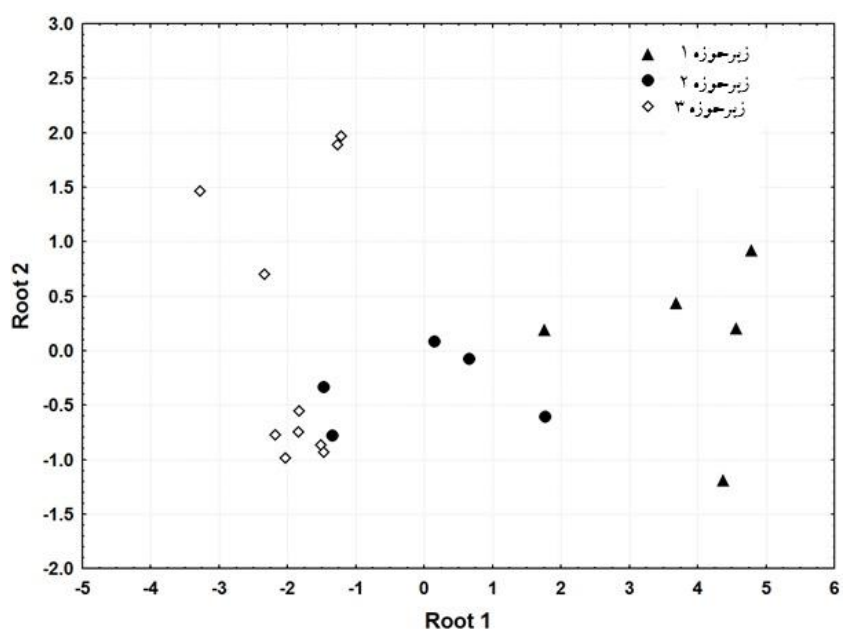

شكل r. نمودار ير اكنش تابع تحليل تشخيص براساس تركيب بهينه ردياب يذيرفتارى مغناطيسى رسوب

قطعيت موجود در تمـام نمونسههـا قابـل قبـول اسـت و نتـايج، اختلاف زيادى با ميانه ندارند (جدول \&) و از سوى ديخر تمـام زيرحوضهها بـا وجـود اينكسه در تعيسين جداكانسه سـهم نسـبى رسوبات داراى نتايج متفاوتى هستند ولى نتايج آنها نزديـك بـه نتايج محاسبات تركيبى است و همه موارد فـوقالـذكر گــواه بــر اعتبار مدل و نتايج اسـت. زيرحوضـه بويـوى جــاى (بـهـ زبـان تركى: رودخانه بزرگ) با توجه به بزرگى و مسـاحت زيساد آن بايد داراى توليد رسوب بيشترى باشد ولى نتايج بهدسـت آمـده حاكى از اين است كه مشاركت اين زيرحوضه در توليد رسـوب

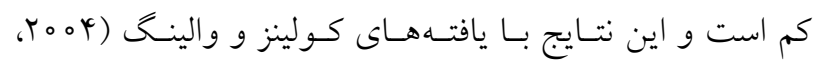

در سه زيرحوضه در صسـكهـاى ه، مه و 90 درصـد محاسـبه شده است كه صدى ينجاه بيانگ ميانه و ميانخين سهم هر منبـع بوده و صدكهاى ه و 90 بيانخر عدم قطعيت موجسود در سـهم رسوب هر منبع هستند. عدم قطعيت بيسين در ينج نمونه خروجسى حوضسه بـهــورت

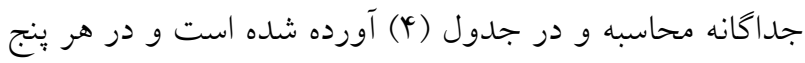
بار محاسبه، زيرحوضه اسياران جــاى بــا اخـتلاف زيـاد از بقيـهـ حوضه ها به عنوان رسوبىترين زير حوضه در اين منطقه شـناخته شده است. اين حوضه با سهم مشاركت بيشتر در توليد رسـوب در سازند خاكستر آتشفشانى قرار گرفته است (شكل () و عـدم 
جدول f. نتايج سهم نسبى رسوبات (\%) در حوضه آبخيز آشان با استفاده مدل بيسين در ينج نمونه خروجى حوضه (صدى بنجاه بيانكر

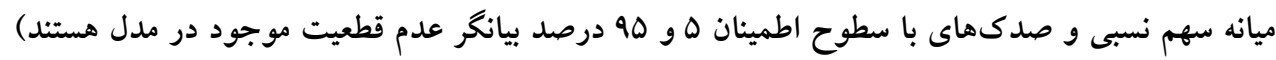

\begin{tabular}{|c|c|c|c|c|c|c|c|}
\hline \multicolumn{8}{|c|}{ سهم نسبى منابع رسوب در حالت جداكانه ٪\% } \\
\hline \multicolumn{4}{|c|}{ نمونه | } & \multicolumn{4}{|c|}{ نمونه ب } \\
\hline $0 \%$ & $0 . \%$ & $90 \%$ & & $0 \%$ & $0 . \%$ & $90 \%$ & \\
\hline YI & Or & $\wedge \circ$ & زيرحوضه 1 & $4 / 9$ & Yq & $\Delta \Delta$ & زيرحوضه 1 \\
\hline$r / 4$ & TQ & $V \circ$ & زيرحوضه r & $r / \Lambda$ & rv & va & زيرحوضه r \\
\hline $1 / 0$ & 19 & er & زيرحوضه r & $4 / 9$ & س & gr & زيرحوضه r \\
\hline \multicolumn{4}{|c|}{ نمونه r } & \multicolumn{4}{|c|}{ نمونه ه } \\
\hline$\Delta \%$ & $0 . \%$ & $90 \%$ & & $0 \%$ & $0 . \%$ & $90 \%$ & \\
\hline$\Lambda \Delta$ & 94 & 99 & زيرحوضه 1 & r & $\Delta Q$ & $\wedge \varphi$ & زيرحوضه 1 \\
\hline س & $r / Q$ & $9 / 9$ & زيرحوضه r & $1 / \mathrm{V}$ & r & 19 & زيرحوضه r \\
\hline 。 & $1 / 9$ & $\Lambda / v$ & زيرحوضه r & 1 & Ir & yo & زيرحوضه r \\
\hline \multicolumn{4}{|c|}{ 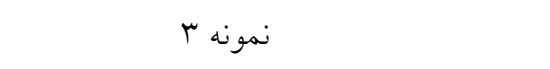 } & \multicolumn{4}{|c|}{ سهم نسبى منابع رسوب در حالت تركيبى } \\
\hline $0 \%$ & $0 . \%$ & $90 \%$ & & $\Delta \%$ & $0 . \%$ & $90 \%$ & \\
\hline rt & 94 & 19 & زيرحوضه 1 & $\Lambda r / q$ & $9 r / 9$ & $91 / 4$ & زيرحوضه 1 \\
\hline $1 / 4$ & 10 & 90 & زيرحوضه r & $0 / r$ & $r / \Lambda$ & $10 / \mathrm{V}$ & زيرحوضه r \\
\hline 。 & Ir & ro & زيرحوضه r & $0 / r$ & $\Delta / V$ & $10 / 0$ & زيرحوضه r \\
\hline
\end{tabular}

نتايج محاسبه سهم نسبى رسوبات در منابع مختلف با استفاده از مدل عدم قطعيت بيسين در شكل (ه) قابـل مشـاهده اسـت. در شكل (ه)، يْنج نمونه رسوب وجـود دارنـد كـه شـمارهخـذارى شدهاند و گرافهاى با عناوين نمونه يك تا ينج، ميـانخين سـهم نسبى رسوب در هر كدام از آنهاست. براساس نتسايج بـهدست آمده از اجراى تركيبى مـدل بيسـين ميـانخين و همجنــين عـدم قطعيت زيرحوضههاى اسـياران، جـوىبنـــ و بويـوى جــاى در توليــ رسـوب بــةترتيـب عبارتنــ از

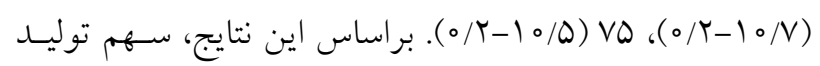
رسوب در زيرحوضههاى مختلف متفاوت بود و با نتايج حاصل از اجراى مدل بهصورت مجزا انطبـاق داشـت. براسـاس نتـايج

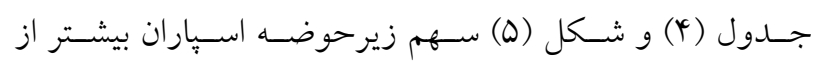

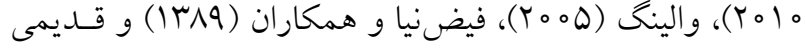

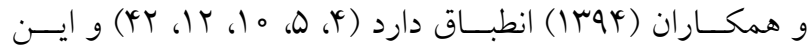
احتمال در رابطه بـا زيرحوضـه بويـوك جــاى وجـود دارد كـهـ بهدليل بزرگ بودن زيرحوضه، امكان به تله افتـادن رسـوبات در هنگام انتقال وجود دارد كه اين خــود، باعـث كـاهش رسـوبات خروجى از حوضه و تهنشينى بيشتر رسوبات فرسايش يافتسه در داخل زير حوضه مىشـود. زيرحوضـه اسـياران (شـماره r) كـهـ بيشترين توليد رسوب را در بين زيرحوضسههـاى ديخــ دارد از

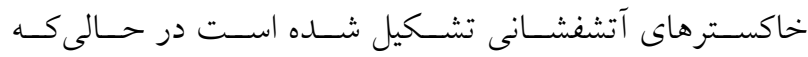
زيرحوضههاى ديخر تركيبى از دو يا سه سازند هسـتند و شـايد

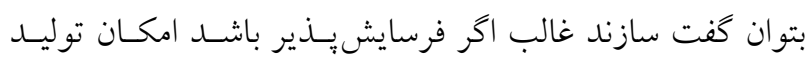
رسوب بيشتر مىشود و زيرحوضه ب داراى يـك سـازند اسـت. 


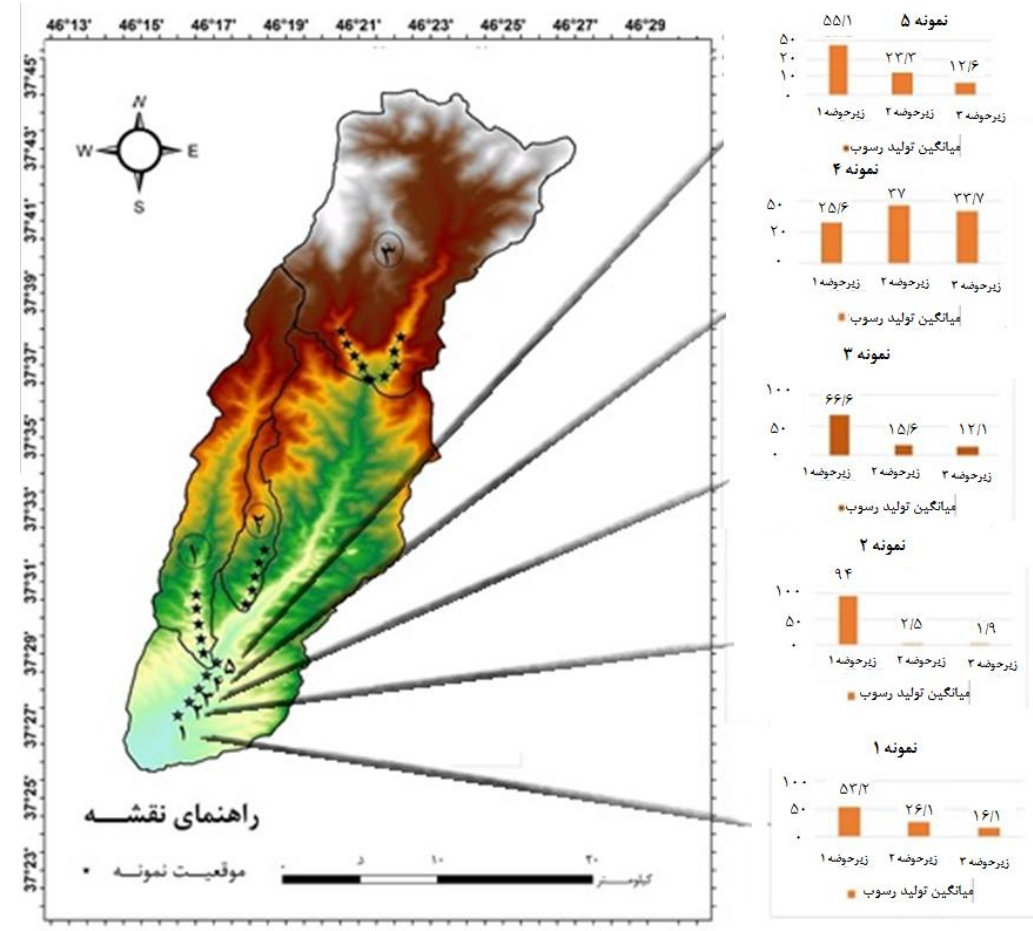

شكل ث. سهم نسبى توليد رسوب از زيرحوضههاى مختلف در حوضه آبخيز آشان (مدل بيسين در بنج نمونه خروجى حوضه محاسبه و

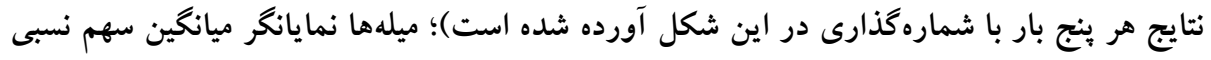
منابع رسوب (100-0\%) در زيرحوضهها هستند

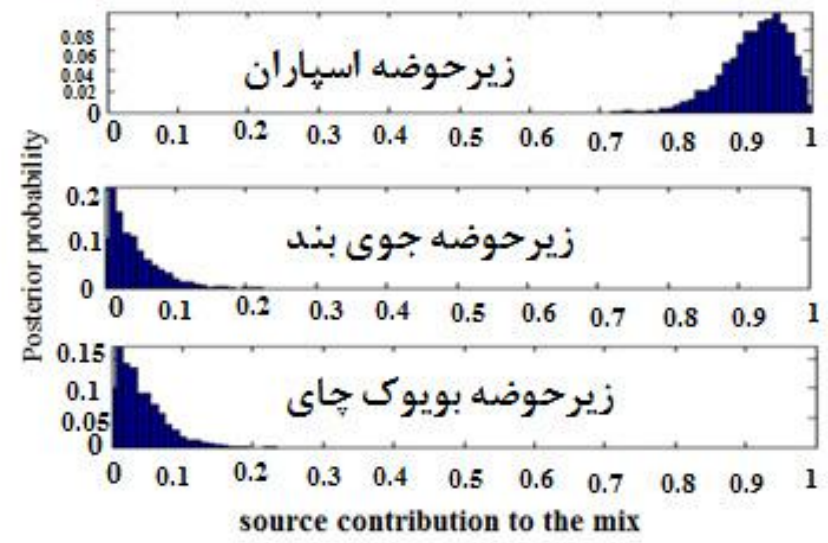

شكل ه. سهم نسبى توليد رسوب به صورت تركيبى با استفاده از مدل عدم قطعيت بيسين در حوضه آبخيز آشان

سهم آنها در توليد رسوب كم شده است و بـا كـاهش آن سـهم

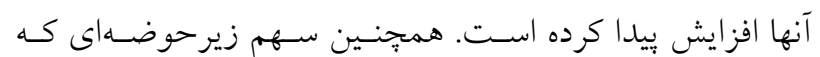

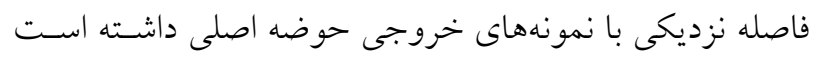

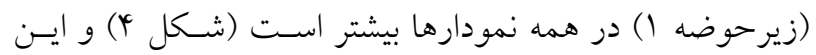
نشان دهنده نقش و اثر فاصله در نتايج تعيين سهم نسبى رسوب

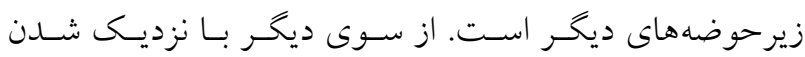
نمونههاى خروجى حوضه اصلى به سمت زيرحوضههـاى بـالا، سهم زيرحوضههاى ب و ب افزايش بيدا مى كند و اين مسى توانـد اثر ناشى از موقعيت نمونها و فاصله برروى سهم نسبى رسوب

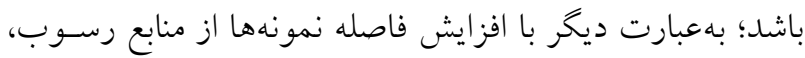


توليد رسوب در حوضه آشان بود؛ اين زيرحوضه بـا دارا بـودن توليد رسوب بيشتر داراى سازند خاكسـترهاى آتشفشـانى بـود. نتايج حاصل از اين يزوهش نمايانخر اثر فاصله در تعيسين سـهم

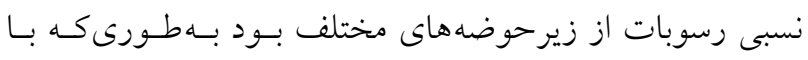
افزايش فاصله منابع از خروجى حوضـه اصـلى، ايسن سـهم كـم مىشود. با توجه به وسعت بالاى منطقه و وجود سـازندهاى بـا بـا

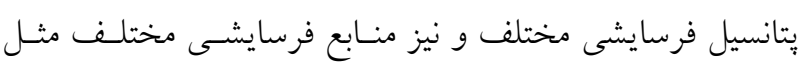
فرسايش سطحى و زيرسطحى در داخل آن، نياز به مطالعات بـا جزئيات بيشتر و آزمون رديابهاى مختلف براى انجام اقدامات مديريتى در هر كدام از زيرحوضههاست و لـذا انجـام بيشـنهاد فوق مىتواند كامهاى بعدى اين بيزوهش باشد.

\section{سياسگزارى}

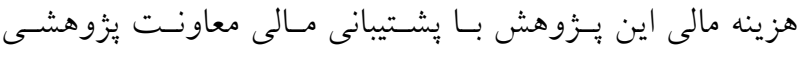

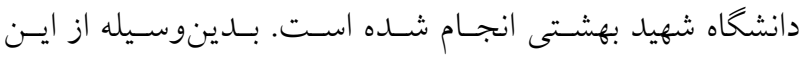
معاونت تشكر و قدردانى بهعمل مى آيد.
است و شايد بتوان كفت اعتبار مدل تركيبى بـا نتـايج بـهدسـت آملده بيشتر شده و اعتماد به مدلهاى تركيبى تقويست مسىشـود. مدل بيسين در يسنج نمونسه خروجسى حوضـه اصـلى بـههمـراه

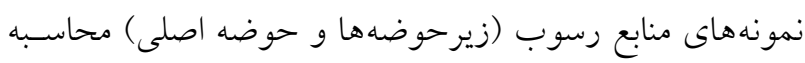
شده و نتايج آن بهصورت سهم نسبى رسوب در سه زيرحوضسه كزارش شـده اسـت. مقــدار سـهم نسـبى رسـوب در هـر سـهـ زيرحوضه بين صفر تا يك متغير است (شكل ه).

\section{نتيجه كيرى}

نتايج يُزوهش نشان داد كه يذيرفتارى مغناطيسى، بهعنـوان يـك ردياب، قابليت تفكيك و جداسـازى منـابع رسـوب را داشـته و بهنوان يك ردياب بهينه در اين يـزّوهش مـورد اسـتفاده قـرار كرفت. در اين بزظوهش، سه ردياب فركانس بالا، فركانس بـايين و فركانس وابسته به بسامد در منبع زيرحوضههـا مـورد آزمـون قرار كرفتند و تنها رديـابهــاى فركـانس بـالا و بـايين قابليـت جداسازى منبع زيرحوضه را داشـتند. براسـاس نتسايج بـهدسـت آمده از مدل تركيبى بيسين، زيرحوضه اســاران، داراى بيشـترين

\section{منابع مورد استفاده}

ا. حكيم خانى، ش. هیז ا. بررسى استفاده از رديابها در رسوبات ريز رودخانهاى با استفاده از تكنيكى منشـايابى (مطالعه مـوردى: حوضه آبخيز يلدشت، شهرستان ماكو). رساله دكترى، دانشكده منابع طبيعى، دانشخاه تهران.

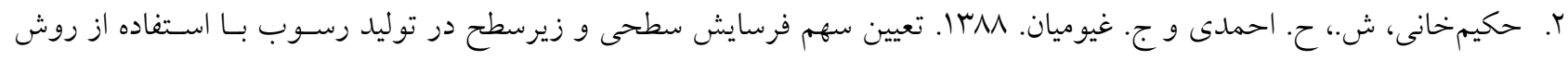

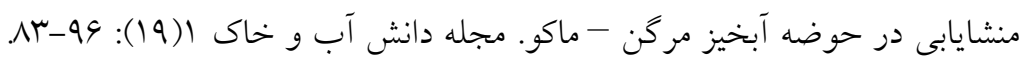

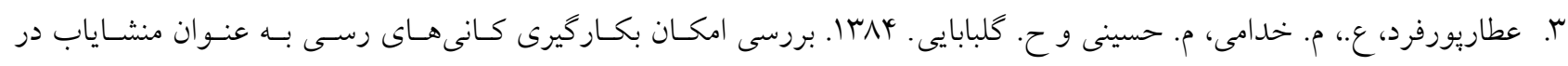

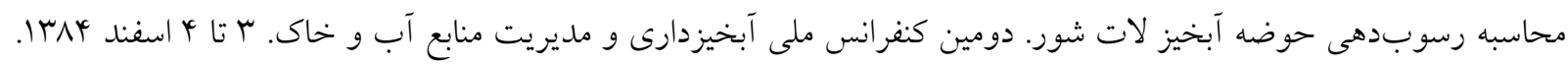

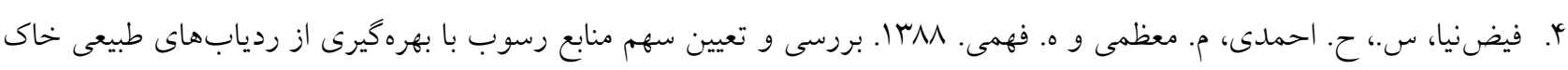

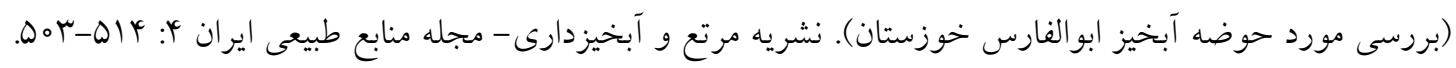

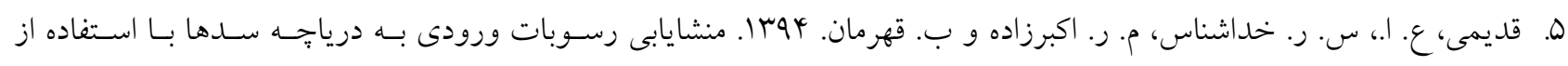

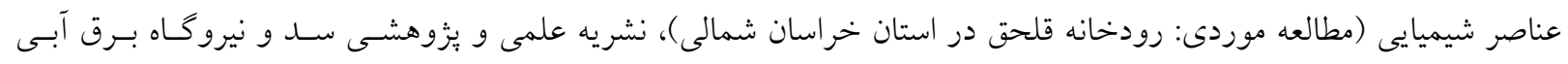

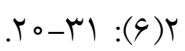
9. نصرتى، ك.، ح. احمدى و ف. شريفى. •وبا. منشايابى منابع رسوب: ارتباط بين فعاليتهاى آنزيمى خاك و رسوب. مجله علـوم 


$$
\begin{aligned}
& \text { و فنون كشاورزى و منابع طبيعى، علوم آب و خاك 09(19): }
\end{aligned}
$$

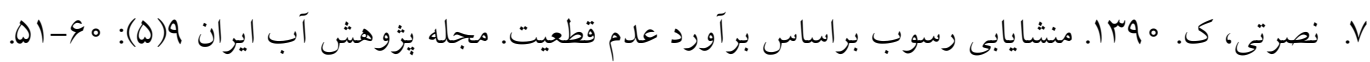

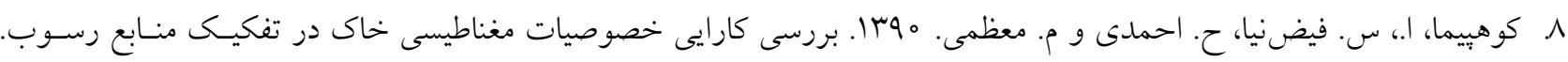

$$
\begin{aligned}
& \text { مجله فيزيك زمين و فضا ||(rV): 19-1| }
\end{aligned}
$$

9. Booth, C. A., M. A. Fullen, J. Walden, J. P. Smith, M. D. Hallett, J. Harris and K. Holland. 2005. Magnetic properties of agricultural top soils of the isle of man: their characterization and classification by factor analysis. Communications in Soil Science and Plant Analysis 36: 1241-1262.

10. Collins, A. L. and D. E. Walling. 2004. Documenting catchment suspended sediment sources: problems, approaches and prospects. Progress in Physical Geography 28: 159-196.

11. Collins, A. and D. Walling. 2007. Sources of fine sediment recovered from the channel bed of lowland groundwater-fed catchments in the UK. Geomorphology 88(1): 120-138.

12. Collins, A. L., D. E. Walling, L. Webb and P. King. 2010. Apportioning catchment scale sediment sources using a modified composite fingerprinting technique incorporating property weightings and prior information. Geoderma 155: 249-261.

13. Dearing, J. A. 1994. Environmental magnetic susceptibility-using the bartington MS2 system. PP: 1-54, Kenilworth, Chi publication.

14. FAO. 1997. Protect and Produce: Putting the Pieces Together. Rome: FAO.

15. Haddadchi, A., K. Nosrati and F. Ahmadi. 2014. Differences between the source contribution of bed material and suspended sediments in a mountainous agricultural catchment of western Iran. Catena 116: 105-113.

16. Hatfield, R. G and B. A. Maher. 2008. Suspended sediment characterization and tracing using a magnetic fingerprinting technique: Bassenthwaite Lake, Cumbria, UK. The Holocene 18: 105-115.

17. Heller, F. and M. E. Evans. 1995. Loess magnetism. Reviews of Geophysics 33: 211-240.

18. Ingrid, F. S., S. R. John and W. F. Stewart. 2002. Quantitative sediment fingerprinting using a Bayesian uncertainty estimation framework. IAHS 276: 443-450.

19. Jenkins, PA., R. W. Duck, J. S. Rowan and J. Walden. 2002. Fingerprinting of bed sediment in the Tay Estuary, Scotland: an environmental magnetism approach. Hydrology and Earth System Sciences 6: 1007-1016.

20. Kouhpeima, A., S. Feiznia, H. Ahmadi, A. Shamsi and H. Ghadimi. 2013. Determining suitable fingerprinting properties for discrimination of sediment sources (Case study: Amrovan and Atary Catchments). Desert 17(3): 255-264.

21. Krein, A., E. Petticrew and T. Udelhoven. 2003. The use of fine sediment fractal dimensions and colour to determine sediment sources in a small watershed. Catena 53: 165-179.

22. Liu, Q., A. P. Robert, J. C. Larrasoaña, S. K. Banerjee, Y. Guyodo, L. Tauxe and F. Oldfield. 2012. Environmental magnetism: Principles and applications. Reviews of Geophysics 50: 1-50.

23. Maher, B. A and R. M. Taylor. 1988. Formation of ultrafine-grained magnetite in soils. Nature 336: 368-370.

24. Maher, B. A., C. Moore and J. Matzka. 2008. Spatial variation in vehicle-derived metal pollution identified by magnetic and elemental analysis of roadside tree leaves. Atmospheric Environment 42: 364-373.

25. Maher, B. A. and R. Thompson. 2009. Quaternary climates, environments and magnetism. PP: 1-398, Cambridge University Press, Cambridge, UK.

26. Martinez-Carreras, N., F. Gallart, J. F. Iffly, L. Pfister, D. E. Walling, A. Krein. 2008. Uncertainty assessment in suspended sediment fingerprinting based on tracer mixing models: a case study from Luxembourg. Sediment Dynamics in changing Environments. IAHS 325: 94-105.

27. Morgan, R. P. C. 2009. Soil and Water Conservation, $3^{\text {th }}$ edition. PP: 1-303, John Wily and Sons.

28. Murray, A. S., R. Stanton, J. M. Olley and R. Morton. 1993. Determining the origins and history of sedimentation in an underground river system using natural and fallout radionuclides. J. Hydrology 146: 341-359.

29. Nosrati, K., G. Govers, H. Ahmadi, F. Sharifi, M. A. Amoozegar, R. Merckx and M. Vanmaercke. 2011. An exploratory study on the use of enzyme activities as sediment tracers: biochemical fingerprints. Int. J. of Sediment Res. 26(2): 136-151.

30. Nosrati, K., G. Govers, B. X. Semmens and E. J. Ward. 2014. A mixing model to incorporate uncertainty in sediment fingerprinting. Geoderma 217: 173-180.

31. Olfield, F., T. A. Rumnery, R. Thompson and D. E. Walling. 1979. Identification of suspended sediment sources by means of magnetic measurements: some preliminary results. Water Resour. 15: 211-218.

32. Poulenard, J., Y. Perrette, B. Fanget, P. Quetin, D. Trevisan and J. M. Dorioz. 2009. Infrared spectroscopy tracing of sediment sources in a small rural watershed (French Alps). Sci. Total Environ. 407: 2808 - 2819.

33. Regan, J. T., O. Fenton and M. G. Healy. 2012. A review of phosphorus and sediment release from Irish tillage 
soils, the methods used to quantify losses and the current state of mitigation practice. Biology and Environment: Proceedings of the Royal Irish Academy 112B: 157-183.

34. Sandgren, P and I. Snowball. 2002. Application of mineral magnetic techniques to paleolimnology, Tracking environmental change using lake sediments. Physical and Chemical Techniques 2: 217-237.

35. Sherriff, S. 2014. Environmental Magnetism: Sediment Source Tracing. PP: 371-2047. Geomorphological techniques. Part 1. British Society for Geomorphology.

36. Small, I. F., J. S. Rowan and S. W. Franks. 2002. Quantitative sediment fingerprinting using Bayesian uncertainty estimation framework. Int. Association of Hydrological Sci. 276: 443-450.

37. Smith, H and D. Dragovich. 2008. Improving precision in sediment source and erosion process distinction in an upland catchment, south-eastern Australia. Catena 72(1): 191-203.

38. SPSS, IBM. 2005. SPSS Base 14 user's guide, Prentice Hall.

39. Sun, D., J. Bloemendal, Z. Yi., Y. Zhu, X. Wang, Y. Zhang, Z. Li, F. Wang, F. Han. and Y. Zhang. 2011. Palaeomagnetic and palaeoenvironmental study of two parallel sections of late Cenozoic strata in the central Taklimakan Desert: Implications for the desertification of the Tarim Basin. Palaeogeography, Palaeoclimatology, Palaeoecology 300: 1-10.

40. Thompson, R. and F. Oldfield. 1986. Environmental magnetism. PP: 1-256. Allen and Unwin press. London.

41. Walden, J and C. K. Ballantyne. 2002. Use of environmental magnetic measurements to validate the vertical extent of ice masses at the Last Glacial Maximum. J. Quaternary Sci. 17: 193-200.

42. Walling, D. E. 2005. Tracing suspended sediment sources in catchments and river systems. Sci. of the Total Environ. 344: 159-184.

43. www.irm.umn.edu. Magnetic susceptibility. 


\title{
Determination of Sub-Basin Contribution in Sediment Yield using Magnetic Susceptibility Properties and Uncertainty Mixing Model (Case Study: Ashan Drainage Basin, Maragheh County)
}

\author{
K. Nosrati ${ }^{* 1}$, M. Amini ${ }^{1}$, A. Haddadchi ${ }^{2}$ and M. R. Zare ${ }^{3}$ \\ (Received: April 14-2016; Accepted: June 20-2016) \\ DOI: 10.18869 /acadpub.jstnar.20.78.141
}

\begin{abstract}
Accelerated soil erosion in Iran causes on-site and off-site effects and identifying of sediment sources and determination of their contribution in sediment yield is necessary for effective sediment control strategies in river basin. In spite of increasing sediment fingerprinting studies uncertainty associated with magnetic susceptibility properties has not been fully incorporated in models yet. The objective of this study is determination of the relative contribution of sediment sources using magnetic susceptibility properties (High frequency, Low frequency and Frequency dependence) incorporated in uncertainty mixing model. For this purpose, 25 bed sediment samples were collected from the outlet of drainage basin and outlet of sub-basins and their magnetic susceptibility was measured and calculated. The results of Kruskal-Wallis test and discriminant function analysis showed that magnetic susceptibility properties can be used as optimum set of tracers in the uncertainty mixing model. The results of Bayesian mixing model indicated that mean (uncertainty range) relative contribution of Sparan, Joyband and Boyoukchay are 92 (83.9-94.8), 2.8 (0.2-10.7), 5.7 (0.2-10.5) percent, respectively. According to these results, the highest amount of sediment yield is related to Sparan sub-basin and these results could be used in soil conservation and management planning.
\end{abstract}

Keywords: Sediment fingerprinting, Ashan drainage basin, Erosion, Bayesian mixing model, Magnetic susceptibility properties.

1.Dept. of Physical Geography, Faculty of Earth Sci., Shahid Beheshti Univ., Tehran, Iran.

2. National Institute of Water and Atmospheric Research, PO Box 8602, Riccarton, Christchurch, New Zealand.

3. Dept. of Physics, Malekashtar Univ., Shahinshahr, Iran.

*: Corresponding Author, Email: K_nosrati@sbu.ac.ir 